\title{
2. RHYTHMICAL CREATIVITY IN DUPLE AND TRIPLE METER OF STUDENTS OF EARLY-SCHOOL EDUCATION IN THE LIGHT OF THEIR STABILISED MUSICAL APTITUDES AND RHYTHM READINESS TO IMPROVISE
}

Maciej Kołodziejski ${ }^{2}$

\begin{abstract}
The article presents the results of (author's) own research on the students of earlyschool education imitation and the rhythmical improvisation in the light of their stabilised musical aptitudes measured with Edwin E. Gordon's AMMA test and also Edwin E. Gordon's readiness to rhythm improvisation readiness record (RIRR). In the first part of the research the students imitated some rhythmical patterns diversified in terms of difficulty in duple and triple meter and the subsequent part concerned guiding the oral rhythmical dialogue (on the $\mathrm{BAH}$ syllable) by the teacher with the application of various rhythmical motives in different metres. The students' both imitative and improvising performances were rated by three competent judges. What was undertaken was searching for the relations between musical aptitudes, improvisation readiness and the pupils' rhythmical imitation and improvisation abilities.
\end{abstract}

Key words: rhythmical improvisation, duple and triple meter, improvisation readiness, stabilized musical aptitudes

\section{Introduction}

The most important skill presented in Gordon's Theory of Music Learning is improvisation called by E. E. Gordon "spontaneous expression of audiation" (Gordon 2003). According to Ch. Azzara "improvisation is necessary [...] because it is through improvisation that students espress their musical thoughts and feelings in the moment of performance” (Azzara 2005: 399). An important part of learning the improvisation is the musical interactions with others with the application of various melodies and rhythms (Azzara 2005: 400). Since the rhythm accompanies a human being in day-to-day life (architecture, literature, art, dance, poetry and music), provides the order to the nature (the sequence of seasons of year, daytime and night-time, sunrise and sunset) and constitutes the element of a human being's existence (breathing in-out, heartbeat, intestinal peristalsis, blood circulation, motion), therefore in this article it has become the subject of the analyses and the starting point of research on the imitation and improvisation of the students' - teachers-to-be of the early education pupils. Rhythm is 'the factor organising the sequence of sounds of a musical piece in time' (Habela 1988: 166) and belongs to the basic musical elements.

Edwin E. Gordon regards rhythm, next to melody (in the tonal aspect) and harmony as the basic musical aptitudes. (Gordon 1999). Rhythm is considered as the crucial point in improvisation since it requires the strong foundation in the form of rhythmical abilities as well as the devotion of the performer in creation of the musical piece in the real time. The creator can easily transforms and

\footnotetext{
2 Associate Professor Habilitated PhD., Karkonosze College from Jelenia Góra, Poland, email: kolomaciej@poczta.onet.pl
} 
locate the sounds displaced in time in specific place, depending on tempo and meter. Thus, rhythm is also related to the issue of time in music (Silverstein, Silverstein and Nunn 2001). Even younger children have the tendency to use the figural or meter application of rhythm, the older ones are able to use both of these representations more flexibly than the younger ones (Paananen 2006).

Segregating music according to motifs, phrases, sequences when we can hear a distinctive accent in the musical piece (i.e. change in dynamics, tone, duration and many others). The feeling of pulse (beat) increases along with the accenting and the number of meter-rhythmical phrases characteristics for this phenomenon and the very sensitivity for the pulse appears very early, as infants are able to tell the difference between the regular and irregular sound sequences. While creating rhythm, children focus their attention on the relative period of the rhythm of speech. Four-year-old children can organise the rhythm spontaneously, i.e. in accordance with the lyrics (Paananem 2006: 350). The meter accent is dependable upon the sensitivity to feeling the impulses which can be divided in two phases: the subjective feeling of pulse and the perception of meter (Paananem 2006: 350). Pulse is related to rhythm but it deals more with accenting the main parts of tempo, in accordance with musical meter and tempo.

The pulse is so important in a musical piece that it is accepted to use numbers to mark it (one, two, three, four). The meter, however, as a rule is the regular appearance of accents in the rhythmical course of musical pieces (Habela 1988: 113). Edwin E. Gordon claims that counting during playing music is only a subjective feeling of the real pulse and tempo. It means that there exist as many tempos of a particular piece of music as the number of people counting the pulse. The main problem in rejecting the habit of counting in music is increasing the audiation competences, thus related to understanding music and hearing its from the inside. Despite the fact that learning music is similar to learning a language, the verbalisation is not going to substitute the musical communication. The music-related sounds are stored as the patterns in structural memory, analogous to poetry or rhyming regardless of understanding these phenomena (Borchgrevink 1993). Undoubtedly, music bears a lot of resemblance to speech (Neuhoff \& Lidji 2014), and to develop the rhythmical competences we can use for example the symmetrical rhythmical dialogue between the pupils in couples and using some Orff's instruments (Králová \& Hudáková 2016).

\section{Research assumptions}

The research is of diagnostic-verification-correlative character. The rhythmical improvisation is an act of both speech (using one's voice as the basic musical instrument, chanting with the application of dynamics, expression, vocal modulation) and music (rhythm, pulse, meter) of the direct and real character (present in improvisation) (teacher-pupil, pupil-pupil), communicative and interactive character (noticing and understanding of people communicating rhythmically, reacting to expression, musical-rhythmical dialogue). Therefore, what was subjectively separated was the rhythmical themes in duple and triple 
meter, being arranged in accordance with the level of difficulty on the grounds of the empirical research by Edwin E. Gordon as easy, moderate and difficult (Gordon \& Woods 1990; Gordon 1991). For performances evaluation, the author's estimation scales were applied (imitation: scale $1^{3}$, scale $2^{4}$, scale 4 ; improvisation: scale 2 , scale $3^{5}$, scale $4^{6}$ ). The graphical order of the research proceedings is presented below.

\footnotetext{
${ }^{3}$ Scale No. 1 continuous (additive) - imitation (compatibility with musical notation)

5 - student ideally repeats the rhythm theme presented by the teacher which is compatible with musical notation;

4 - student almost exactly repeats the rhythm theme presented by the teacher;

3 - student repeats most of rhythm values presented in the theme presented by the teacher;

2 - student repeats only some of the rhythm values present in the rhythm theme presented by the teacher;

1 - student repeats only single rhythm values form the rhythm theme, which significantly differs from the musical notation;

0 - student does not repeat the presented theme.

${ }^{4}$ Scale No. 2 continuous (additive) - imitation/improvisation - criterion: tempo and pulse compatibility (beat)

5 - imitation/improvisation is always compatible with the defined tempo, maintained in the defined pulse (beat), student imitates/improvises after hearing the rhythm included in 4 macro-bits and knows that their imitation/improvisation lasts in time of 4 macro-bits (regardless of the meter);

4 - imitation/improvisation is almost always compatible with the defined tempo, almost always maintained in the defined pulse (beat), student imitates/improvises after hearing the rhythm included in 4 macro-bits and knows that their imitation/improvisation also lasts in time of 4 macro-bits (regardless of the meter) ;

3 - imitation/improvisation is only sometimes compatible with the defined tempo and partially maintained in the defined pulse (beat), student not always imitates/improvises after hearing the 4 macro-bits and sometimes does not perform the imitation/improvisation lasting in time of 4 macro-bits (regardless of the meter) either shortens/extends it or moves on to another macro-bit;

2 - imitation/improvisation is mostly incompatible with the defined tempo (student often hurries or slows) and is seldom maintained in the defined pulse (beat), student does not always imitates/improvises after hearing 4 macro-bits and frequently does not perform the imitation/improvisation lasting in time of 4 macro-bits (regardless of the meter), either shortens/extends it or moves on to another macro-bit;

1 - imitation/improvisation is almost always incompatible with the defined tempo (student often hurries or slows) and is frequently not maintained in the defined pulse (beat), student hardly imitates/improvises after hearing 4 macro-bits and very rarely performs the imitation/improvisation lasting in time of 4 macro-bits (regardless of the meter), either shortens/extends it moving on to another macro-bit;

$\mathbf{0}$ - imitation/improvisation is always incompatible with the defined tempo (student almost always hurries or slows) and never maintains the performance in the defined pulse (beat). Student does not know when to begin the imitation/improvisation and hardly ever imitates/improvises during 4 macro-bits (regardless of the meter), either significantly shortens it or extends it moving on to another macro-bit not feeling the four-beat phrasing.

${ }^{5}$ Scale No. 3 continuous (additive) - criterion: improvisation

5 - student runs a rhythm dialogue with the teacher using the extended ornamentations depending on applied in the musical communication the dynamics, the fragmentation end extension, the applied rhythm phenomena (i.e. syncope, triplet, dotted rhythm and even the anacrusis), eagerly experiments with rhythm;

4 - student runs a rhythm dialogue with the teacher using various ornamentations, however, they are not significantly extensive and the student often returns to the rhythm familiar to him, even so, tries to experiment with rhythm;

3 - student sometimes reaches beyond the safe frames of mixing the schemes used by the teacher, the more difficult are replaced with the easier ones which he knows well and feels safe with, student is reluctant to experiment with the rhythm;

2 - most of the responses are improvised but the applied solutions are repeatable and familiar (or heard before), student does not exceed their familiar and uncomplicated themes;

1 - most of the responses are the ones repeated after the teacher, yet at times some alternations can be heard but what is suggested are the schemes used by the teacher, i.e. in the different order;

0 - student imitates rather than improvises, the improvised reactions are random and uncertain.

${ }^{6}$ Scale No. 4 additive. Criterion: expression and modulation

5 - imitation/improvisation exceeds the expectations with reference to certainty of performance, fluency, articulation and vocal intonation in conversation, is highly expressive, students uses vocal modulation depending on the conversation;

4 - imitation/improvisation is compatible with expectations with reference to certainty of performance, fluency, articulation and vocal intonation in conversation, is expressive, vocal modulation heard fragmentarily;
} 


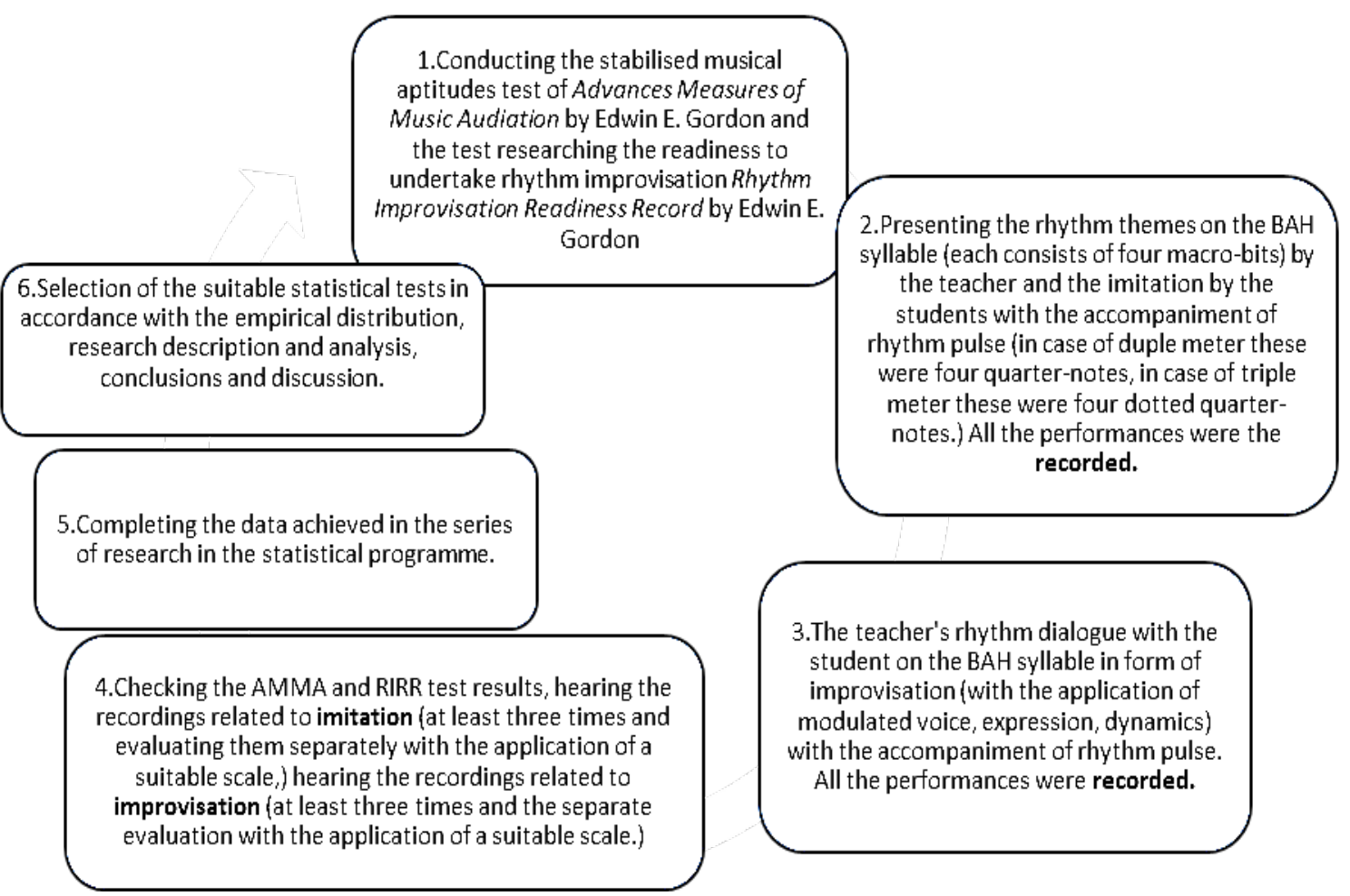

Source: author's own elaboration

The following themes were used in the imitation research. In improvisation the themes were invented in hand.

Collation 1 Rhythm themes used in the imitation in duple meter (starting with easy)

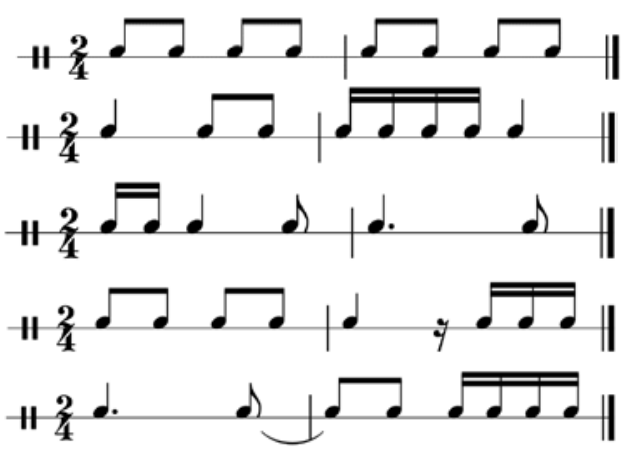

Source: (Gordon \& Woods 1990)

Collation 2 Triple rhythmical themes used in imitation (starting with easy)

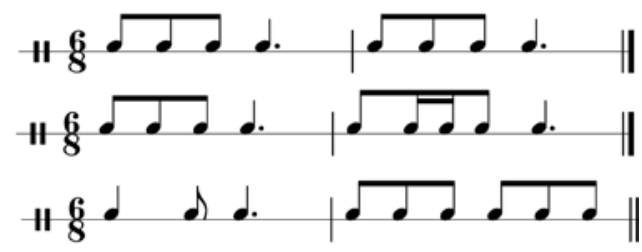

3 - imitation/improvisation demonstrates elements of certainty of performance, fluency, articulation and vocal intonation in conversation, average expression, poor vocal modulation;

2 - imitation/improvisation hesitant, lack of performance certainty, partial elements of the application of articulation and vocal intonation in conversation, poor expression, infinitesimal vocal modulation;

1 - improvisation hesitant, lack of performance certainty, the application of articulation hardly heard, lack of changes in vocal intonation, lack of expression, lack of vocal modulation;

0 - improvisation hesitant, lack of self-confidence in performance, lack of articulation, lack of vocal intonation, lack of vocal modulation, maintaining (voice) at one level. 


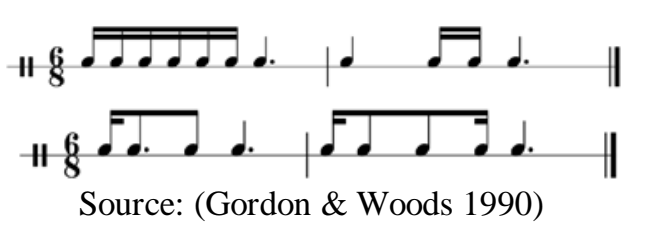

3. The paradigm applied and the academic theory as the research constructive axis

What is applied is the post-positivist paradigm and the quantitative approach. The theoretical background is the theory of music learning by Edwin E. Gordon the assumptions of which are presented in short: (Gordon 1997; 1999a, 1999b; Bonna \& Trzos \& Kołodziejski 2014):

- musical aptitudes are developed until about the age of 9, then they get stabilised and sustain at this level until the end of life, it does not, however, refer to some achievements (i.e. singing, playing musical instruments or music improvisation which can be developed),

- musical aptitudes constitute a strong determinant of musical achievements, but pupils with poor aptitudes shall represent also the poor achievements, whereas pupils with high aptitudes shall not represent themselves with top achievements (i.e. when related to improvisation),

- rhythmical themes (as well as tonal ones) construct the pupils; musical glossary necessary to develop the readiness to improvisation and the very ability to improvise,

- not everyone has the necessary readiness to develop the musical improvisation (rhythmical and harmonic) but it is worth stimulating this readiness through the special musical training,

- despite their differences, musical aptitudes and achievements are strictly related to each other; similarly to people's other potentials, there exists a variety of levels of musical aptitudes dispersed among the humankind. The potential of learning music and achieving successes in music learning is based on the musical cognition, in other words audiation, which reaches far beyond the ordinary imitation and leads to understanding music (Gordon 2007; Gordon 2000).

a) The method of

- testing (Edwin E. Gordon's AMMA and RIRR tests)

- didactic evaluation with the use of continuous estimation scales (additive),

- statistical method (the Shapiro-Wilk test of normality in frequentist statistics, the Wilcoxon's non-parametric test of variables differences and the Spearman's rank correlation coefficient).

b) Sample selection

- a group of volunteers recruited among 80 students of early-school education (2 males and 31 females, two persons with higher musical education). c) Research main question

Do, and to what extend, the stabilised musical aptitudes determine the readiness to rhythmical improvisation and the ability to imitate and improvise 


\section{short rhythmic themes in duple and triple meter? \\ d) Research detailed questions}

1. What is the level of stabilised musical aptitudes of the early-school education students under the research?

2. Are there any (and what) any differences between the results of tonal and rhythmical sub-test within AMMA test in the research group?

3. Do the students possess the indispensable readiness to undertake the rhythmical improvisation?

4. Is there a relation between the stabilised musical aptitudes and the readiness to undertake the rhythmical improvisation?

5. Is there (and how strong is) a relation between some particular AMMA subtests and the abilities of rhythmical imitation and improvisation in duple and triple meter in the group of students under research?

6. Are there any and (if there are) how big are the differences in the abilities of rhythmical imitation and improvisation in duple and triple meter in the group of students under research?

7. Are there any relations between the readiness to rhythmical improvisation and the abilities of rhythmical imitation and improvisation in duple and triple meter in the group of students under research?

\section{e) Research hypotheses}

$H_{G}$ : Stabilised musical aptitudes, especially rhythm-related, do determine the students' readiness to undertake the rhythmical improvisation and also the level of both imitative and improvisational abilities. I assume that the improvisation in triple meter shall obtain poorer mean values than in duple meter. It is due to the low level of society's music-practising and also the problems with the perception of meter as well as musical phrasing.

$H_{1}$ : I assume that the level of stabilised musical aptitudes will be generally average and low, in accordance with the prior research explorations in this field.

$H_{2:}$ I assume that the values related to rhythm will be statistically higher and more significant than in the tonal sub-test range. The research indicate that at the moment of stabilising the musical aptitudes, the rhythmical aspect is placed at a higher level than the tonal one.

$H_{3:} I$ assume that most of the students under research possess the necessary readiness to undertake the rhythmical improvisation.

$\mathrm{H}_{4:}$ I assume that there is a relation between the stabilised musical aptitudes and the readiness to rhythmical improvisation.

$H_{5:}$ I assume that there is a relation between the stabilised musical aptitudes and abilities of rhythmical imitation and improvisation.

$H_{6:}$ I assume that there happen some differences between the abilities of rhythmical imitation and improvisation in duple meter to the disadvantage of the triple meter.

$H_{7:}$ I assume that there is a relation between the readiness to musical improvisation and the abilities of rhythmical imitation and improvisation in the 


\section{f) Research variables and indicators}

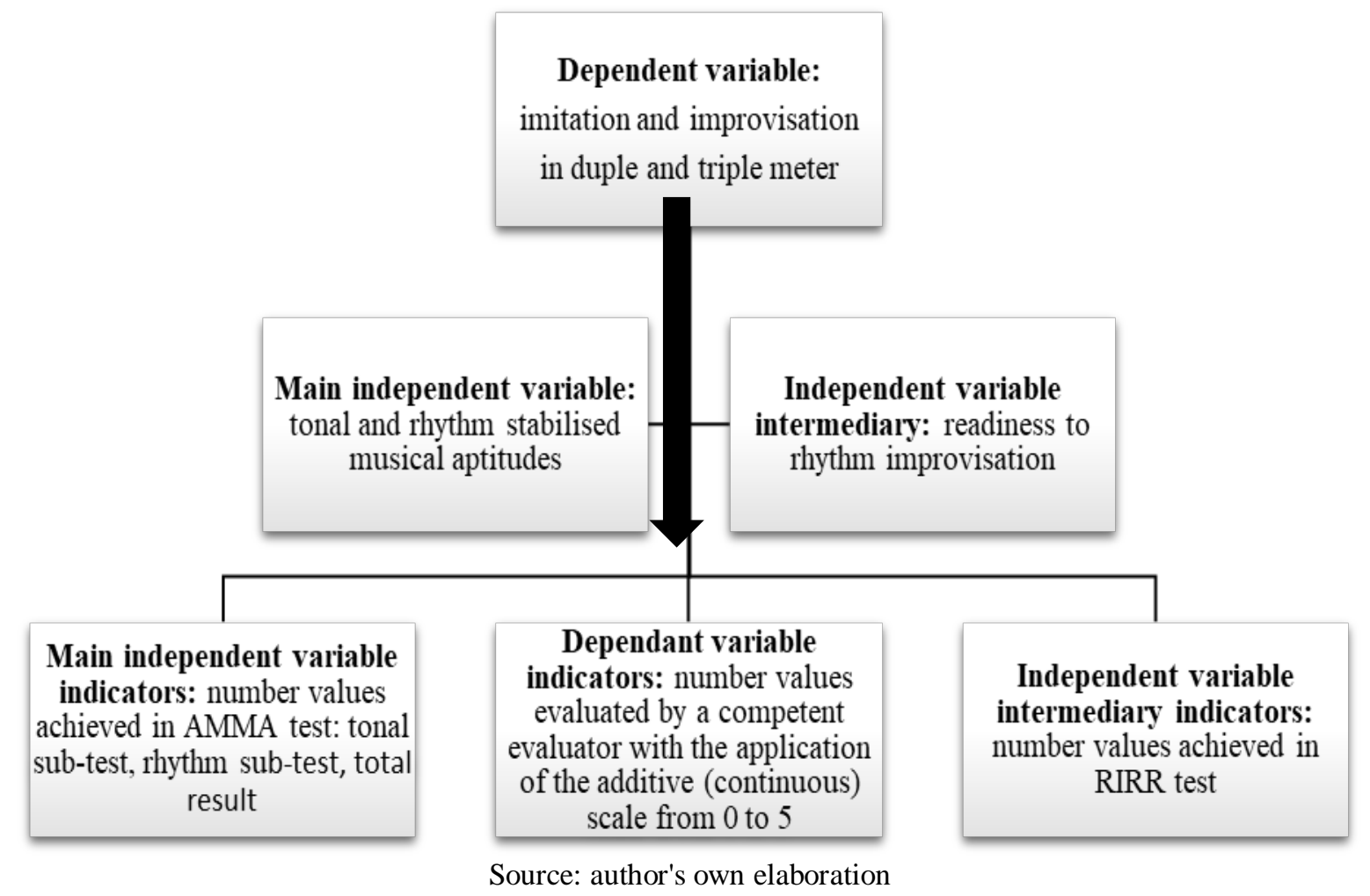

\section{g) Musical aptitudes and the readiness to improvisation}

In order to learn about the dependable variable distribution, the ShapiroWilk test was used and whose formula can be presented in the form of the following equation.

$$
W=\frac{\left[\sum_{i} a_{i}(n)\left(X_{n-i+1}-X_{i}\right)\right]^{2}}{\sum_{j=1}^{n}\left(X_{j}-\bar{X}\right)^{2}}
$$

Null hypothesis (the difference between the analysed parameters or distribution equals zero) was presented for the Shapiro-Wilk test assuming that the dependable variable distribution in the students' rhythmical improvisation research is normal. What was calculated was $\mathrm{p}=0.0288$ therefore it was lower than $\mathrm{p}<0.05$, thus the null hypothesis on the distribution normality had to be rejected. To calculate the differences between the variables the $t$ Wilcoxon was used. This test is only used when we wish to compare two (only two) dependable groups with each other, that is two estimation variables. The data distribution obtained with the AMMA test of stabilised musical aptitudes by Edwin E. Gordon presents the following results.

Table 1 Basic descriptive statistics for the AMMA and RIRR tests by Edwin E. Gordon in the

\begin{tabular}{cccccc} 
& \multicolumn{5}{c}{ group of 33 people under research } \\
\hline Nonal & 33 & 23.27 & 16 & 29 & 3.16 \\
\hline Rhythm & 33 & 26.27 & 21 & 31 & 2.92 \\
\hline Total AMMA & 33 & 49.55 & 39 & 59 & 5.10 \\
\hline RIRR & 33 & 30.91 & 18 & 40 & 4.00 \\
\hline & Source: author's own elaboration on the basis of conducted research
\end{tabular}


The rhythmical sub-test produced higher values than the tonal sub-test. The $\mathrm{p}$-value to compare between the AMMA sub-tests was $\mathrm{p}=0.0002$ for $\mathrm{p} \leq 0.05$ where the difference of the means was $(-4.497,-1.503)$ respectively. Comparison with the application of test $t$ indicated that for the confidence level $95 \%$, with the averages difference $(-4.497,-1.503)$, the value $\mathrm{p}=0.0002$ was achieved. The difference between the tonal and rhythm sub-test within AMMA test is statistically significant for $p \leq 0.05$. The mean of RIRR test results presents that the readiness to improvisation in the volunteer group is quite substantial - only one person in the group does not have it. The level of musical aptitudes in the group under research is the following: none of them has achieved the level of high results, 31 people have the average aptitude and 2 people have the low aptitudes.

Chart 1 Level of musical aptitudes in the group of 33 people under research

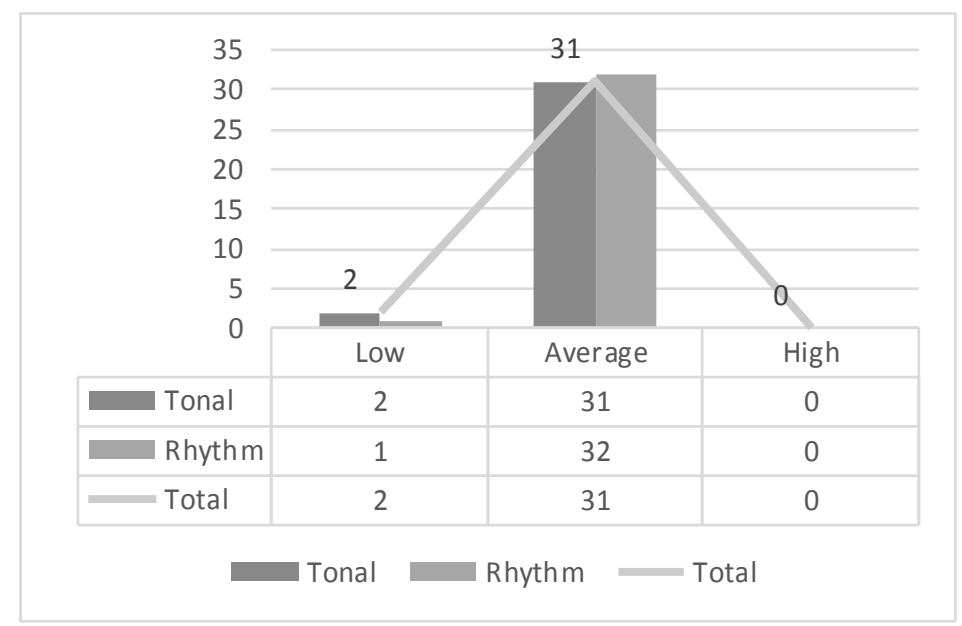

Source: author's own elaboration on the basis of conducted research

Intercorrelation within the AMMA sub-tests confirmed the high efficiency of this diagnostic tool. It was placed between the tonal sub-test and the total result $\rho=0.849$ and this result is statistically different from $0(p=0)$, rhythm and the total result $\rho=0.826$ and this result is statistically different from $0(p=0)$.

The result of the intercorrelation test between the rhythm sub-test AMMA and RIRR is $\rho=0.42$ and this result is statistically different from $0(p=0.014)$, between the rhythm sub-test within AMMA and RIRR test is $\rho=0.38$ and this result is statistically different from $0(p=0.029)$. The highest correlation was noted with the application of Spearman's rank correlation test between Total AMMA and RIRR, and it is $\rho=0.48$ and this result is statistically different from $0(\mathrm{p}=0.004)$. It is illustrated with the chart below.

Chart 2 Correlations between Total AMMA and RIRR

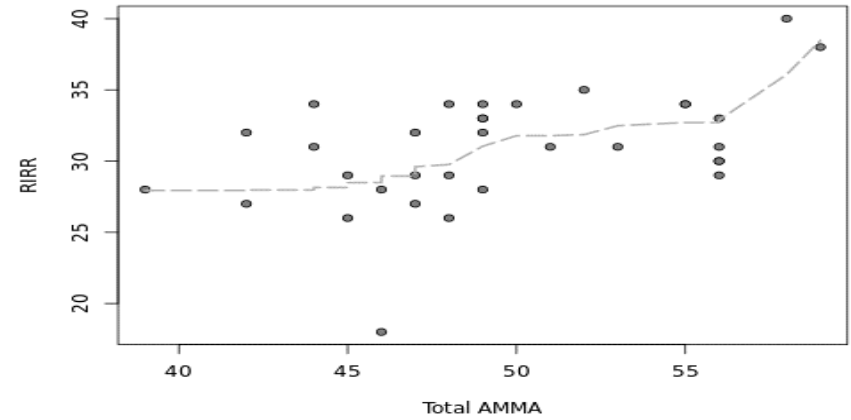

Source: author's own elaboration on the basis of conducted research 


\section{Imitation and improvisation in duple and triple meter - research results description and analysis}

The respective analyses consider the added points for the imitation in duple meter where it was evaluated with the use of three scale of five performances (each performance was graded $0-5$ points, which makes maximally 75 points after adding the three scales - both in imitation in duple meter, imitation in triple meter, improvisation in duple meter and improvisation in triple meter.) The respective added results of three scales related to improvisation are presented in the chart below.

Chart 3 Results related to imitation and improvisation in the group under research

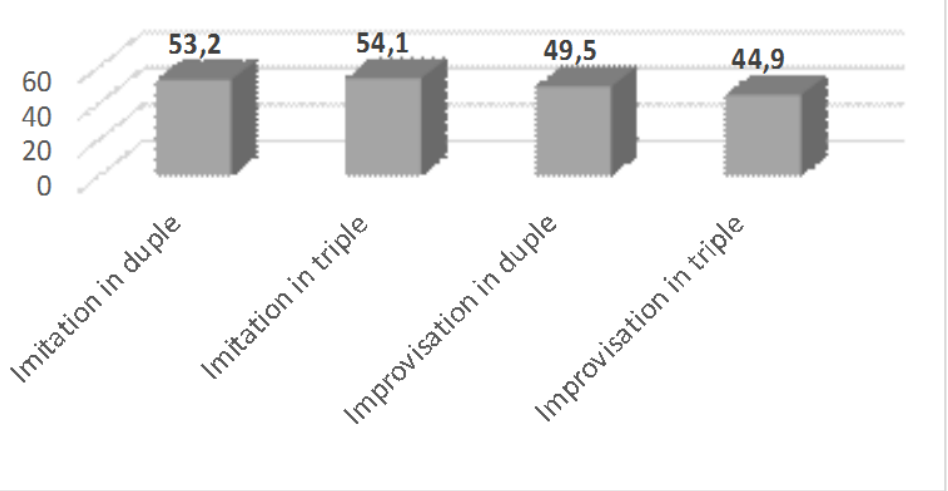

Source: author's own elaboration on the basis of conducted research

The following differences between the results were observed:

- between the competences of imitation in duple and triple meter the value $p$ for the comparison between groups was $\mathrm{p}=0.7622$ at $95 \%$ confidence interval with the difference of the means $(-6.884,5.066)$, which is statistically insignificant. The Basic statistics in this field present as follows:

Table 2 Basic comparative statistics between imitation in duple and triple meter

\begin{tabular}{lcccccc}
\hline Skills & Minimum & 1st Qu. & Median & Mean & 3rd Qu. & Maximum \\
\hline $\begin{array}{l}\text { Imitation } \\
\text { in duple }\end{array}$ & 13 & 45 & 55 & 53.21 & 62 & 72 \\
\hline $\begin{array}{l}\text { Imitation } \\
\text { in triple }\end{array}$ & 24 & 46 & 58 & 54.12 & 62 & 74 \\
\hline
\end{tabular}

- between the competences of improvisation in duple and triple meter the value $p$ for the comparison between groups is $\mathrm{p}=0.1694$ at $95 \%$ confidence interval with the difference of the means $(-2.018,11.23)$, which is statistically insignificant. The Basic statistics in this field present as follows:

Table 3 Basic comparative statistics between improvisation in duple and triple meter

\begin{tabular}{lcccccc}
\hline Skills & Minimum & 1st Qu. & Median & Mean & 3rd Qu. & Maximum \\
\hline $\begin{array}{l}\text { Improvisation } \\
\text { in duple }\end{array}$ & 28 & 42 & 50 & 49.52 & 58 & 74 \\
\hline $\begin{array}{l}\text { Improvisation } \\
\text { in triple }\end{array}$ & 13 & 34 & 46 & 44.91 & 55 & 75 \\
\hline
\end{tabular}

- between the competences of imitation and improvisation in duple meter the value $\mathrm{p}$ for the comparison between groups is $\mathrm{p}=0.2115$ at $95 \%$ confidence interval with the means difference $(-2.155,9.549)$. The difference between 
groups is not statistically significant. The Basic statistics is illustrated in the table below.

Table 4 Basic comparative statistics between imitation and improvisation in duple meter

\begin{tabular}{|c|c|c|c|c|c|c|}
\hline Skills & Minimum & 1st Qu. & Median & Mean & 3rd Qu. & Maximum \\
\hline $\begin{array}{l}\text { Imitation in } \\
\text { duple }\end{array}$ & 13 & 55 & 55 & 53.21 & 62 & 72 \\
\hline $\begin{array}{l}\text { Improvisation } \\
\text { in duple }\end{array}$ & 28 & 50 & 50 & 49.52 & 58 & 74 \\
\hline
\end{tabular}

Source: author's own elaboration on the basis of conducted research.

- between the competences of imitation and improvisation in triple meter the value $\mathrm{p}$ for the comparison between groups is $\mathrm{p}=0.081$ at $95 \%$ confidence interval with the means difference $(2.48,15.944)$. The difference between groups is statistically significant. It is illustrated in the table below.

Table 5 Basic comparative statistics between imitation and improvisation in triple meter

\begin{tabular}{lcccccc}
\hline Skills & Minimum & 1st Qu. & Median & Mean & 3rd Qu. & Maximum \\
\hline $\begin{array}{l}\text { Imitation } \\
\text { in triple }\end{array}$ & 24 & 46 & 58 & 54.12 & 62 & 74 \\
\hline $\begin{array}{l}\text { Improvisation } \\
\text { in triple }\end{array}$ & 13 & 34 & 46 & 44.91 & 55 & 75 \\
\hline & Source: author's own elaboration on the basis of conducted research &
\end{tabular}

- between the imitative competences in duple meter and improvisation in triple meter the value $\mathrm{p}$ for the comparison between the groups is $\mathrm{p}=0.016$ at $95 \%$ confidence interval for the means difference $(1.601,15.005)$. The comparison with the application of test $t$ displayed that the difference between groups is statistically significant for $p \leq .05$ with the advantage of the imitation in duple meter. It is illustrated in the table below.

Table 6 Basic comparative statistics between imitation in duple meter and improvisation in

\begin{tabular}{lcccccc}
\multicolumn{7}{c}{ triple meter } \\
\hline Skills & Minimum & 1st Qu. & Median & Mean & 3rd Qu. & Maximum \\
\hline $\begin{array}{l}\text { Imitation } \\
\text { in duple }\end{array}$ & 13 & 45 & 55 & 53.21 & 62 & 72 \\
\hline $\begin{array}{l}\text { Improvisation } \\
\text { in triple }\end{array}$ & 13 & 34 & 46 & 44.91 & 55 & 75 \\
\hline
\end{tabular}

- between the imitative competences in triple meter and improvisation in duple meter the value $\mathrm{p}$ for the comparison between the groups is $\mathrm{p}=0.1229$ at $95 \%$ confidence interval for the means difference $(-1.28,10.492)$. The difference between groups is not statistically significant. It is illustrated in the table below.

Table 7 Basic comparative statistics between imitation in triple meter and improvisation in duple meter

\begin{tabular}{lcccccc}
\hline Skills & Minimum & 1st Qu. & Median & Mean & 3rd Qu. & Maximum \\
\hline $\begin{array}{l}\text { Imitation } \\
\text { in triple }\end{array}$ & 24 & 46 & 58 & 54.12 & 62 & 74 \\
\hline $\begin{array}{l}\text { Improvisation } \\
\text { in duple }\end{array}$ & 28 & 42 & 50 & 49.52 & 58 & 74 \\
\hline & \multicolumn{5}{l}{ Source: author's own elaboration on the basis of conducted research } &
\end{tabular}

\section{Correlations between AMMA test and the imitative and improvisational competences measured with the application of estimation scales \\ What was noted was the following correlations between the particular sub- tests within AMMA test and RIRR test versus imitative and improvisational competences measured with the application of continuous estimation scales (the}


particular scales were added here ${ }^{7}$ ).

Table 8 Correlations between the applied tests and particular imitative and improvisational

\begin{tabular}{lllll} 
& \multicolumn{2}{c}{ competences } & \\
& $\begin{array}{l}\text { Imitation } \\
\text { in duple }\end{array}$ & $\begin{array}{l}\text { Imitation } \\
\text { in triple }\end{array}$ & $\begin{array}{l}\text { Improvisation } \\
\text { in duple }\end{array}$ & $\begin{array}{l}\text { Improvisation } \\
\text { in triple }\end{array}$ \\
\hline Tonal & $\rho=0.17$ & $\rho=0.19$ & $\rho=0.10$ & $\rho=-0.07$ \\
\hline Rhythm & $\rho=0.30^{*}$ & $\boldsymbol{\rho}=\mathbf{0 . 4} * *$ & $\boldsymbol{\rho}=\mathbf{0 . 4 3} * * *$ & $\rho=0.28$ \\
\hline AMMA Total & $\rho=0.28$ & $\boldsymbol{\rho}=\mathbf{0 . 3 4 * * * *}$ & $\rho=0.31^{*}$ & $\rho=0.11$ \\
\hline RIRR & $\rho=0.20$ & $\rho=0.14$ & $\rho=0.25$ & $\rho=0.25$ \\
\hline
\end{tabular}

Source: author's own elaboration on the basis of conducted research

There exist some moderate correlations, statistically significant for $\mathrm{p} \leq .05$, between the sub-test of stabilised rhythm-related musical aptitudes (within AMMA test) and the competences related to imitation in triple meter $(\rho=0.4)$ and improvisation in duple meter $(\rho=0.43)$, as well as the total result of AMMA test and the imitation in triple meter $(\rho=0.34)$. What noted was some partial correlations between the rhythm sub-test and the imitation in duple meter ( $\rho=0.30$, close to statistical significance) as well as the AMMA total result and the improvisation in duple meter $(\rho=0.31$, close to statistical significance.) Because most of the group under research has the readiness to improvisation, the relations between RIRR test results and the imitation and improvisation competences were not noted. Moreover, there also exist high and very high correlations between the added results for imitation and improvisation competences. This is illustrated in the table below.

Table 9 Correlations between particular ranks within imitation and improvisation competences

\begin{tabular}{lcccc}
\hline & Imitation in duple & Imitation in triple & $\begin{array}{c}\text { Improvisation } \\
\text { in duple }\end{array}$ & $\begin{array}{c}\text { Improvisation } \\
\text { in triple }\end{array}$ \\
\hline Imitation in duple & - & $\rho=0.87$ & $\rho=0.73$ & $\rho=0.68$ \\
\hline Imitation in triple & $\rho=0.87$ & - & $\rho=0.70$ & $\rho=0.73$ \\
\hline $\begin{array}{l}\text { Improvisation } \\
\text { in duple }\end{array}$ & $\rho=0.73$ & $\rho=0.70$ & - & $\rho=0.81$ \\
\hline $\begin{array}{l}\text { Improvisation } \\
\text { in triple }\end{array}$ & $\rho=0.68$ & $\rho=0.73$ & $\rho=0.81$ & - \\
\hline
\end{tabular}

Source: author's own elaboration on the basis of conducted research

If we, however, split the particular scales into the competences of imitation $\left(\mathbf{S}_{\mathbf{1} \text { - imitation, }} \mathbf{S}_{\mathbf{2} \text { - tempo and beat, }} \mathbf{S}_{\mathbf{4} \text { - expression and vocal modulation }}\right)$ and improvisation $\left(\mathbf{S}_{\mathbf{2}}\right.$ - tempo and pulse compatibility, $\mathbf{S}_{\mathbf{3}}$ - improvisation, $\mathbf{S}_{\mathbf{4}}$ - expression and vocal modulation), the significant differences in the comparative aspect are presented below.

With relation to imitation in duple meter:

- $\mathbf{S}_{1}$ - imitation $=\mathbf{S}_{\mathbf{2}}$ - tempo and beat, comparing with the use of test t, for $95 \%$ confidence with the means difference $(-1.011,3.556), p=0.2696$ and it is not statistically significant, which stands for the homogeneous distribution, close to each other,

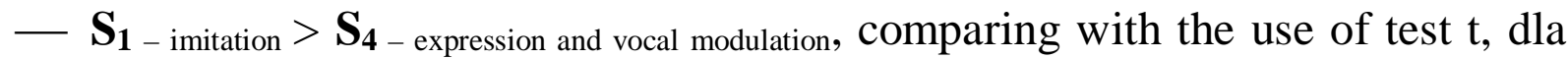
$95 \%$ confidence with the means difference $(1.596,5.797)$, where $p=0.0008$, the

\footnotetext{
${ }^{7 *}$ close to statistical significance $(\mathrm{p}=0.08)$

** statistically significant for $\mathrm{p}=0.02$

$* * *$ statistically significant for $\mathrm{p}=0.01$

$* * * *$ statistically significant for $\mathrm{p}=0.04$.
} 
difference between groups is statistically significant, which stand for the homogeneous distribution, far from each other,

- $\mathbf{S}_{2}$ - tempo and beat $>\mathbf{S}_{\mathbf{4}}$ - expression and vocal modulation, comparing with the use of test $\mathrm{t}$, dla $95 \%$ confidence with the means difference $(0.253,4.596), \mathrm{p}=0.0293$, where the difference between groups is statistically significant, which stands for homogeneous distribution, far from each other.

With relation to imitation in triple meter:

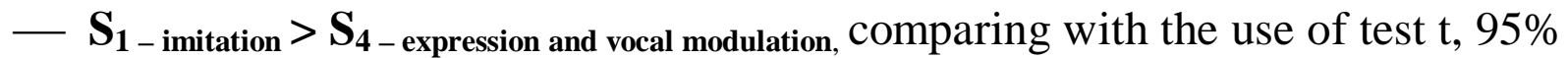
confidence with the means difference $(0.688,4.585), \mathrm{p}=0.0088$, and the difference between groups is statistically significant, which stands for heterogeneous distribution, far from each other.

- $\mathbf{S}_{1 \text {-imitation }}=\mathbf{S}_{2 \text { - tempo and beat, }}$ comparing with the use of test $\mathrm{t}, 95 \%$ confidence with the means difference $(-3.875,0.906), p=0.2189$, and the difference between groups is statistically significant, which stands for heterogeneous distribution, close to each other.

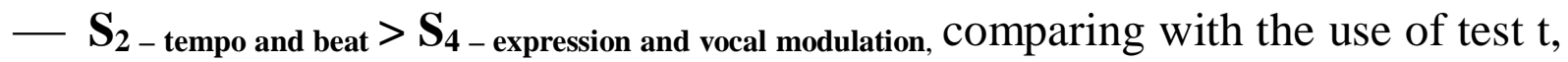
$95 \%$ confidence with the means difference $(1.851,6.391), \mathrm{p}=0.0000$, thus the difference between groups is statistically significant, which stands for heterogeneous distribution, far from each other.

With relation to improvisation in duple meter:

- $\mathbf{S}_{2}$ - tempo and pulse compatibility $>\mathbf{S}_{3}$ - improvisation, comparing with the use of test $t$, $95 \%$ confidence with the means difference (3.924, 8.924), $\mathrm{p}=0.0001$, thus the difference between groups is statistically significant, which stands for heterogeneous distribution, far from each other,

$-\mathbf{S}_{2}$ - tempo and pulse compatibility $>\mathbf{S}_{\mathbf{4}}$ - expression and vocal modulation, comparing with the use of test $t, 95 \%$ confidence with the means difference $(0.973,5.512)$, $\mathrm{p}=0.0058$, thus the difference between groups is statistically significant, which stands for heterogeneous distribution, far from each other,

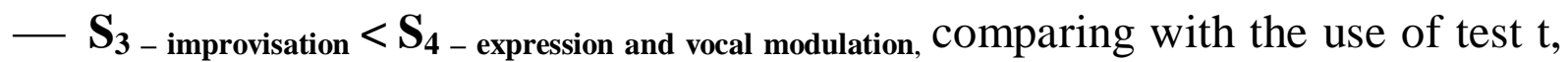
$95 \%$ confidence with the means difference $(-5.455,-0.908), p=0.0069$, thus the difference between groups is statistically significant, which stands for heterogeneous distribution, far from each other.

With relation to improvisation in triple meter:

- $\mathbf{S}_{2 \text { - tempo and pulse compatibility }}>\mathbf{S}_{\mathbf{3}}$-improvisation, comparing with the use of test t, $95 \%$ confidence with the means difference $(1.597,7.676), \mathrm{p}=0.0034$, thus the difference between groups is statistically significant, which stands for heterogeneous distribution, far from each other.

- $\mathbf{S}_{\mathbf{2}}$ - tempo and pulse compatibility $=\mathbf{S}_{\mathbf{4}}$ - expression and vocal modulation, comparing with the use of test $t, 95 \%$ confidence with the means difference $(-0.59,4.772), p=0.1238$, thus the difference between groups is not statistically significant, the distribution of this variable is homogeneous,

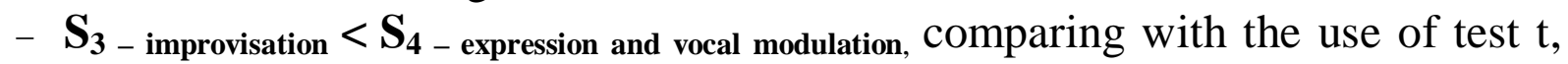
$95 \%$ confidence with the means difference $(-5.045,-0.046), p=0.046$, thus the difference between groups is statistically significant, which stands for 
heterogeneous distribution, far from each other.

As presented above, students are far better when it comes to imitation (in both duple and triple meter) with tracing the musical notion and maintaining the tempo and compatibility with pulse rather than with expression and vocal modulation in the improvisational activities. In improvisation, however, all its components (tempo and pulse compatibility, expression and vocal modulation) seem to be evaluated better than the very improvisation.

\section{Random qualitative analyses of cases}

Only one person with the raw result in test RIRR that was 18 did not possess the readiness to rhythm improvisation. The person's results in AMMA test were respectively for Tonal test 12 and Rhythm=22. This person has the average tonal competences and the rhythm competences below the average and very poor feeling of tempo and pulse $(\mathrm{M}=2,8)$ expression during imitation $(M=2,4)$ and even poorer improvisation competences in duple meter (at the level $\mathrm{M}=2$ ) as well as poorer results in the improvisation in triple meter (below 2 points in the mean). The results of people with distinctive musical aptitudes (but still not the high ones) are presented in the table below.

Table 10 People (musicians and non-musicians) with distinctive musical aptitudes and their results in imitation and improvisation

\begin{tabular}{|c|c|c|c|c|c|c|c|c|}
\hline \multicolumn{4}{|c|}{ AMMA } & \multirow[t]{2}{*}{ RIRR } & \multicolumn{2}{|c|}{ Imitation } & \multicolumn{2}{|c|}{ Improvisation } \\
\hline L.p. & Tonal & Rhythm & Total & & Duple meter & Triple meter & Duple meter & Triple meter \\
\hline 1 & 28 & 31 & 50 & 38 & 72 & 74 & 74 & 75 \\
\hline 2 & 29 & 29 & 47 & 40 & 70 & 69 & 62 & 57 \\
\hline Mean $^{8}$ & 28.5 & 30 & 48.5 & 39 & 71 & 71.5 & 68 & 66 \\
\hline 1 & 25 & 31 & 56 & 29 & 53 & 59 & 44 & 47 \\
\hline 2 & 23 & 30 & 53 & 31 & 43 & 53 & 51 & 47 \\
\hline 3 & 27 & 29 & 56 & 30 & 69 & 71 & 58 & 58 \\
\hline 4 & 25 & 30 & 55 & 34 & 62 & 59 & 58 & 53 \\
\hline 5 & 27 & 29 & 56 & 33 & 63 & 65 & 44 & 39 \\
\hline 6 & 24 & 28 & 52 & 35 & 44 & 46 & 45 & 31 \\
\hline 7 & 28 & 27 & 55 & 34 & 37 & 35 & 31 & 26 \\
\hline 8 & 27 & 29 & 56 & 31 & 55 & 62 & 65 & 54 \\
\hline 9 & 27 & 29 & 56 & 30 & 53 & 51 & 51 & 24 \\
\hline Mean $^{9}$ & 25.9 & 29.1 & 55 & 31.9 & 53.2 & 55.6 & 49.6 & 42.1 \\
\hline
\end{tabular}

Source: author's own elaboration on the basis of conducted research

The students of the professional musicians achieve considerably higher results both in the competence test, readiness to improvisation and all the particular aptitudes (imitative and improvisational). The most significant difference can be observed between the improvisation results in triple meter (musicians - non-musicians). Moreover, it is noticed that the considerably higher values are achieved in imitation than in improvisation.

\footnotetext{
${ }^{8}$ Music majors.

${ }^{9}$ Non music majors.
} 


\section{Conclusions and research discussion}

- musical competences do not constitute the only independent variable of imitation and improvisation achievements since it was only between the rhythm competences and the imitation abilities (in triple meter $\rho=0.4$ for $\mathrm{p}=0.02$ ) and the improvisation (in duple meter $\rho=0.43$ for $p=0.01$ ) that the statistical significance was noted. It can be considered as random the correlation between rhythm competences and the improvisation in triple meter $(\rho=0.28$, statistically insignificant),

- there are no relations between RIRR test results and musical imitation and improvisation. In my opinion, it is related to the fact that most of the research group was in possession of the necessary readiness to rhythm improvisation, but another possibility must be taken into consideration, that is the procedure of improvisation itself is based the application of numerous rhythm combinations (dotted rhythm, triplets, using the syncopation, ligatures to extend the rhythm values as well as the set of anacrusis apart from the application of acknowledged solutions with the use of sixteenth notes, eighth notes, quarter notes the substitutes of pauses and the combination of these rhythm values.) The test RIRR itself bases on the time patterns which include (whole notes, dotted-whole notes, half notes ad quarter notes) (comp: Gordon 1998 20-21). The imitation competences in duple and triple meter are higher than the improvisation competences in triple meter (but it is not applicable tp duple meter). Between all the results related to imitation and improvisation there happen high and strong correlations,

- stabilised musical aptitudes in the research group o3 33 students are generally at the moderate level (1 person obtained the low result) with the total mean for the tonal sub-test $M=23.2$, rhythm $M=26.2$ and total $M=49.5$, whereas the students musically educated achieved a higher mean (tonal $\mathrm{M}=28.5$, rhythm $M=30$, total $M=58.5$ ). In Edwin E. Gordon's research the research people achieved similar results to AMMA test (musicians: tonal $\mathrm{M}=28.3$, rhythm $\mathrm{M}=30.8$, total $\mathrm{M}=59.1$; non-musicians: tonal $\mathrm{M}=23.8$, rhythm $\mathrm{M}=26.6$, total $\mathrm{M}=50.6$ ) (Gordon 1989: 44). In Maciej Kołodziejski's prior research (2010:13) the following results were achieved (musicians: tonal $M=27.2$, rhythm $M=29.7$, total $\mathrm{M}=57.5$; non-musicians: tonal $\mathrm{M}=23.9$, rhythm $\mathrm{M}=25.9$, total $\mathrm{M}=49.8$ ). The differences between tonal and rhythm sub-tests are statistically significant for the advantage of the rhythm sub-test, similarly to the research by E. E. Gordon (1989) or M. Kołodziejski (2010; 2011).

- the inter-correlations achieved within the AMMA test presented the relations at the average level (according to Guilford scale), the relations at higher level were presented by E. E. Gordon (1989) in his research on test standardisation, - the mean achieved in RIRR test was $M=30.9$ total, in the musicians' group $M=39$, the person without the readiness to improvisation $M=18$, and the rest of the people with the outstanding aptitudes $M=31.3$. The achieved results confirm that in RIRR test the group under research obtained slightly higher values than the ones observed in E. E Gordon's research (1998: 56-57) where: the groups of secondary education students $M=27.4$, in the other groups $M=27.7$, 
- there exist average ( $\rho=0.48$ for $p=0.04$ ) but distinctive relations between AMMA test and RIRR test, which is confirmed by E. E. Gordon's research (1998) where lower but significant correlations were achieved, where $r=0.21$ and between RIRR and rhythm sub-test $r=0.24$,

- when all the results with the application of some particular estimation scales are compared, the improvisation aptitudes are the poorest. Therefore, students are better at imitating rhythm patterns according to the music notation, then these ones evaluated with the use of scale related to maintaining the tempo and pulse and very poor are the competences of expressive interpretation of rhythm and vocal modulation depending on the intentions of the person running the rhythm-related dialogue. At the same time, it was not clearly indicated that the students under research are better at using the rhythm creativity in duple meter than in triple meter. However, it is the imitation in duple meter that is performed the best $(\mathrm{M}=53.2)$ and the improvisation in triple meter the poorest $(\mathrm{M}=44.9)$.

\section{Bibliography}

1. Azzara, Ch. (2005). Understnding Music Through Improvisation, [In:] The Development and Practical Application of Music Learning Theory, Ed. M. Runfola and C. Crump Taggart, GIA Publications, Inc. Chicago.

2. Barton, S., Getz, L., \& Kubovy, M. (2017). Systematic Variation in Rhythm Production as Tempo Changes. „Music Perception”, 34(3), 303-312.

3. Bonna, B. \& Trzos, P. A., \& Kołodziejski, M., Musical-educational research of the adaptation of E. E. Gordon's theory of music learning in Poland, [in] „Review of Artistic Education”, George Enescu University of Arts, Iasi, Romania, Nr 7-8, pp. 7-19, 2014.

4. Borchgrevink, H. M. (1993). [Music, brain and medicine]. Tidsskrift For Den Norske Laegeforening: Tidsskrift For Praktisk Medicin, Ny Raekke, 113(30), 3743-3747.

5. Gordon E. E. (2000). Rhythm . Contrasting the implications of Audiation and Notation. Chicago: GIA Publications.

6. Gordon, E. E. (1991). Jump Right In: The Music Curriculum, Rhythm Register Book One Revised Ed. GIA Publications, Inc. Chicago.

7. Gordon, E. E. \& D. G. Woods (1999). Zanurz sie w program nauczania muzyki : działania w kolejności uczenia się: podręcznik dla nauczycieli, WSP: Bydgoszcz

8. Gordon E. E. (2003). Learning Sequences in Music: Skill, Content, and Patterns. Chicago: GIA Publications.

9. Gordon, E. E. Manual for the Advanced Measures of Music Audiation, GIA Publications, Inc. Chicago 1989.

10. Gordon, E. E. (1999). Sekwencje uczenia się w muzyce. Umiejętności, zawartość i motywy. Bydgoszcz: WSP.

11. Gordon, E. E. (1998). Harmonic Improvisation Readiness Record and Rhythm Improvisation Reaadiness Record. Chicago: GIA Publications.

12. Habela, J. (1988). Słowniczek muzyczny. PWM: Warszawa. 
13. Králová, E., \& Hudáková, J. (2016). Creative Interdisciplinary Math Lessons by Means of Music Activities, „Review of Artistic Education”, George Enescu University of Arts, Iasi, Romania, Nr 11-12, pp. 290-296, 2016.

14. Kołodziejski, M. (2010). Stabilised musical aptitudes as measured in Polish pedagogy students using Advanced Measures of Music Audiation test by Edwin E. Gordon, The Spaces of Creation, Scholar Research Journal, Vol. 13, p. 8-17. 15. Kołodziejski, M. (2011). Koncepcja Edwina E. Gordona w powszechnej edukacji muzycznej, PWSZ: Płock.

16. Neuhoff, J. G., \& Lidji, P. (2014). Language Familiarity, Expectation, and Novice Musical Rhythm Production. Language \& Speech, 57(4), 563-572. doi:10.1177/0023830914520837

17. Paananen, P. (2006). The development of rhythm at the age of 6-11 years: non-pitch rhythmic improvisation. Music Education Research, 8(3), 349-368. doi:10.1080/14613800600957487

18. Silverstein, A., Silverstein, V., \& Nunn, L. S. (2001). The Sound of Music. In , Hearing (Senses \& Sensors) (p. 40). Lerner Publishing Group. 